\title{
PERANCANGAN ALAT PELEPAS PIN GUIDE VANE PADA MESIN FUJI VF-IRS 69054L1 DI PLTA IR. P.M NOOR
}

\author{
${ }^{(1)}$ Sobar Ihsan, ${ }^{(2)}$ Adliansyah,, ${ }^{(3)}$ Ahmadil Amin, ${ }^{(4)}$ Marlina Ayu Lestari \\ (1)(2)(4)Program Studi Teknik Mesin, Universitas Islam Kalimantan MAAB \\ (3)Program Studi Teknik Mesin, Politeknik Sinarmas Berau Coal \\ Email :sobar.uniska@gmail.com,adli_sbto@yahoo.co.id, \\ ahmadilamin718@gmail.com, marlina.aayu@gmail.com
}

\begin{abstract}
Abstrak
Dalam memproduksi energi lisrik, PLTA Ir P.M Noor melakukan pemeliharaan periodik yaitu 8.000 jam kerja (Annual Inspection), 20.000 jam kerja (General Inspection) dan 40.000 jam kerja (Major Inspection). Dalam Pelaksanaan Pemeliharaan Periodik Major Inspection, PLTA Ir P.M Noor diharuskan melakukan pekerjaan sesuai dengan jadwal dan target yang telah ditetapkan oleh Unit Pelaksana Pengendalian Pembangkit Barito. Dalam pelaksanaan Major Inspection dilakukan pelepasan seluruh komponen pada turbin, termasuk pada guide vane. Untuk melepaskan guide vane diperlukan pelepasan komponen-komponen yang mendukungnya antara lain pin guide vane, arm, dan bushing. Pelaksanaan pelepasan pin guide vane yang berupa baja besi cukup susah untuk dilepaskan dikarenakan bentuk pin guide vane yang sedemikian rupa yaitu vertikal dengan guide vane sehingga menyebabkan permasalahan timbul ketika melepaskannya dari rangkaian pendukung guide vane. Permasalahan lain yang muncul yaitu saat jumlah pin guide vane yang berjumlah 20 buah (jumlah guide vane 20 buah), sehingga membutuhkan waktu yang cukup lama $( \pm 2$ hari), waktu yang lama ini akan mempengaruhi pekerjaan pelepasan komponen lainnya, sehingga akan menyebabkan resiko keterlambatan dalam penyelesaian pelaksanaan Major Inspection.

Pada penelitian hasil perhitungan batas minimum von mises $0.00000478 \mathrm{MPa}$ dan maksimum 245.413 MPa dan nilai von mises stress masih dibawah dari nilai yield strength material yaitu $245.413 \mathrm{MPa}$. Sedangkan manfaat secara finansial dapat mempercepat pelaksanaan Major Inspection yang dalam pelaksanaan pekerjaan melepas pin guide vane memerlukan waktu \pm 2 hari, dapat dilakukan dalam \pm 3 jam saja.
\end{abstract}

Kata kunci :Perancangan, tool, pin guide vane

\section{Abstract}

In producing electrical energy, PLTA Ir P.M Noor performs periodic maintenance, namely 8,000 working hours (Annual Inspection), 20,000 working hours (General Inspection) and 40,000 working hours (Major Inspection). In the Implementation of Periodic Major Inspection Maintenance, PLTA Ir P.M Noor is required to carry out work according to the schedule and targets set by the Barito Power Plant Control Implementing Unit.

During the Major Inspection, all components of the turbine are removed, including the guide vane. To remove the guide vane, it is necessary to remove the components that support it, including the guide vane pin, arm, and bushing. The removal of the pin guide vane which is in the form of iron steel is quite difficult to remove because the shape of the 
guide vane pin is in such a way that it is vertical with the guide vane, causing problems to arise when removing it from the guide vane supporting circuit. Another problem that arises is when the number of guide vanes is 20 pieces (the number of guide vanes is 20), so it takes a long time ( \pm 2 days), this long time will affect the work of removing other components, so it will cause a risk of delay in the completion of the implementation of the Major Inspection.

In the study the results of the calculation of the minimum limit of von Mises 0.00000478 MPa and a maximum of 245,413 MPa and the value of von Mises stress is still below the yield strength of the material, which is 245,413 MPa. Meanwhile, the financial benefits can accelerate the implementation of the Major Inspection, which in carrying out the work of removing the pin guide vane takes \pm 2 days, it can be done in \pm 3 hours.

Keywords: Design, tool, pin guide vane

\section{PENDAHULUAN}

Pembangkit Listrik Tenaga Air atau yang biasa disingkat PLTA adalah pembangkit listrik yang mengandalkan energi potensial dan kinetik dari air untuk menghasilkan energi listrik. Dalam sejarah pembangkit listrik, tenaga air telah digunakan sejak zaman kuno untuk menggiling gandum dan melakukan tugas lainnya. Di akhir abad ke-19, generator listrik dikembangkan dan saat ini dapat dipasangkan dengan hidraulis. Pada tahun 1878, pembangkit listrik air pertama dunia dikembangkan di Cragside, Northumberland, Inggris oleh William George Armstrong. Pembangkit listrik pertama buatan Edison (Pembangkit Vulcan Street, mulai beroperasi 30 September 1882 di Appleton, Wisconsin, dengan keluaran sebesar 12.5 kilowatt.

PLTA sebagai pembangkit listrik ini bekerja dengan cara memanfaatkan air dengan mengubah energi potensial dan energi kinetik air (pada waduk atau bendungan) untuk dapat memutar turbin yang dihubungkan dengan generator dan kemudian dapat menghasilkan energi listrik. Bisa dikatakan bahwa PLTA merupakan salah satu jenis pembangkit yang murah dan sangat ramah lingkungan.

PLTA Ir. P. M Noor atau dulunya lebih dikenal sebagai PLTA Riam Kanan, adalah salah satu sub-unit pembangkit listrik yang ada di
Kalimantan Selatan dibawah PT PLN (Persero) Unit Pelaksana Pengendalian Pembangkitan Barito. Sejak awal beroperasi pada tahun 1973, sebagai penyuplai tenaga listrik utama dengan daya mampu yang dihasilkan yaitu sebesar $3 \times 10$ Mega Watt. Seiring meningkatnya kebutuhan listrik, PLTA Ir. P.M Noor tidak lagi menjadi penyuplai utama tenaga listrik, namun keberadaannya tetap sangat penting, terutama sebagai black start kelistrikan sistem Barito.

Dalam memproduksi energi lisrik, PLTA Ir P.M Noor melakukan pemeliharaan periodik yaitu 8.000 jam kerja (Annual Inspection), 20.000 jam kerja (General Inspection) dan 40.000 jam kerja (Major Inspection). Dalam Pelaksanaan Pemeliharaan Periodik Major Inspection, PLTA Ir P.M Noor diharuskan melakukan pekerjaan sesuai dengan jadwal dan target yang telah ditetapkan oleh Unit Pelaksana Pengendalian Pembangkit Barito. Hal ini dikarenakan untuk menjaga ketersediaan pasokan sistem kelistrikan Barito. Pelaksanaan Major Inspection dilakukan dengan membongkar seluruh komponen turbin, untuk kemudian dilakukan inspeksi dan penggantian pada sparepart yang telah aus.

Dalam pelaksanaan Major Inspection dilakukan pelepasan seluruh komponen pada turbin, termasuk pada guide vane. Untuk melepaskan guide vane diperlukan pelepasan komponen- 
komponen yang mendukungnya antara lain pin guide vane, arm, dan bushing. Pelaksanaan pelepasan pin guide vane yang berupa baja besi cukup susah untuk dilepaskan dikarenakan bentuk pin guide vane yang sedemikian rupa yaitu vertikal dengan guide vane sehingga menyebabkan permasalahan timbul ketika melepaskannya dari rangkaian pendukung guide vane. Permasalahan lain yang muncul yaitu saat jumlah pin guide vane yang berjumlah 20 buah (jumlah guide vane 20 buah), sehingga membutuhkan waktu yang cukup lama ( \pm 2 hari), waktu yang lama ini akan mempengaruhi pekerjaan pelepasan komponen lainnya, sehingga akan menyebabkan resiko keterlambatan dalam penyelesaian pelaksanaan Major Inspection. Selama ini, juga beberapa kali terjadi kendala, antara lain bengkoknya pin karena kesalahan posisi melepas pin tersebut justru pin akan terjepit dan merusak bukan hanya pin, tetapi juga liner dari guide vane dan arm. Hal ini akan memperlambat proses pelepasan rangkaian guide vane dan proses pemasangan selanjutnya. Untuk mengatasi hal-hal tersebut di atas, maka dibuatlah suatu terobosan agar mampu mempercepat pekerjaan pelepasan pin guide vane dan lebih aman dalam pelaksanaannya

Tool Pelepas Pin Guide Vane adalah alat yang didesain sedemikian rupa, yang digunakan untuk melepaskan pin tersebut. Pelepasan pin guide vane yang semula menggunakan pengungkit, dan dengan special tool pelepas pin dapat dilepas dengan menggunakan prinsip ulir, sehingga lebih memudahkan dan mempersingkat waktu melakukan pelepasan pin guide vane dan dengan demikian pelaksanaan pemeliharaan Major Inspection bisa lebih tepat waktu, dan menjaga kehandalan sistem kelistrikan di Kalimantan Selatan.

\section{METODE PENELITIAN}

Agar penelitian dapat berjalan secara sistematis, maka diperlukan rancangan penelitian / langkah-langkah dalam penelitian. Adapun flowchart penelitian sebagai berikut :

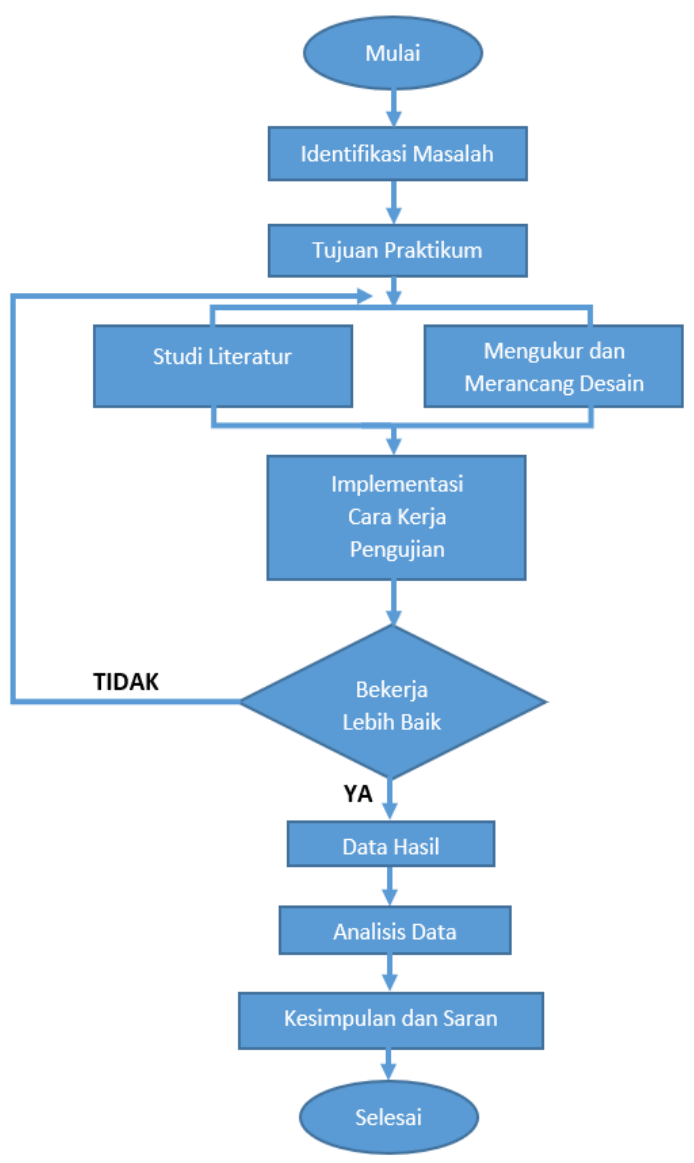

Diagram Alur Penelitian

\section{Pengukuran dan Rancangan}

Tool Pelepas pin Guide Vane ini didesain agar dapat memenuhi kriteria seperti berikut:

1. Dapat digunakan diruang kerja yang sempit.

2. Dapat mengangkat pin guide vane secara Vertikal lurus.

3. Dapat digunakan dengan tenaga sekecil mungkin.

Dengan berdasarkan kriteria diatas, maka dilakukan perancangan untuk mendesain peralatan yang diperlukan sesuai dengan kebutuhan melepas Pin Guide Vane pada saat major Inspection. 
Bagian dalam tools berupa pengait yang disesuaikan dengan bentuk pin guide vane dan terhubung dengan sistem ulir dibagian atas tools. Dibagian ulir dipasang mur yang ketika dikencangkan maka akan menarik naik pengait yang ada didalam tools.

Sistem ulir dibuat ukuran besar untuk menyesuaikan tarikan pengait untuk mengangkat pin guide vane dan kekuatan kunci yang memutar mur pada ulir. Ukuran tool dibuat dalam bentuk gambar desain 2 dimensi dan 3 dimensi yang terlampir pada gambar dibawah ini:

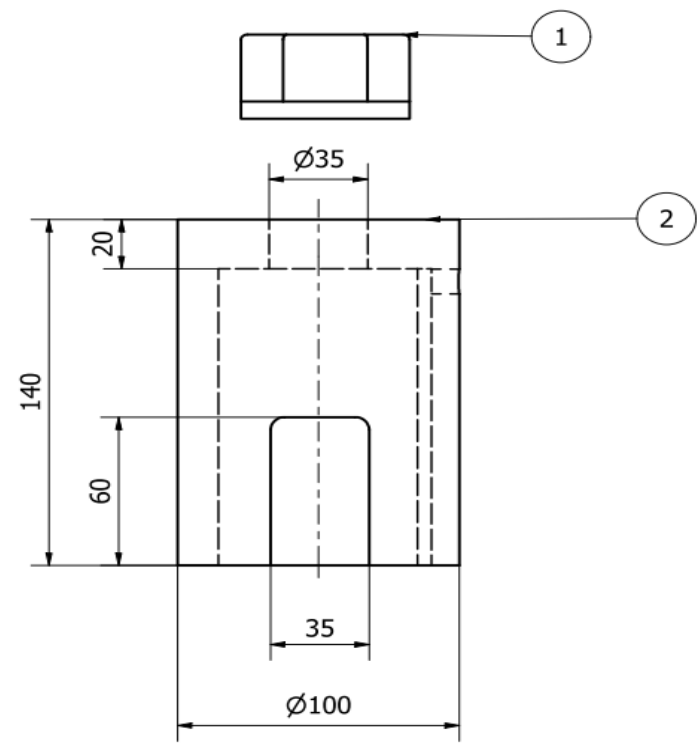

Gambar 3.2 Desain 2D (Tabung) Tool Pelepas Pin Guide Vane

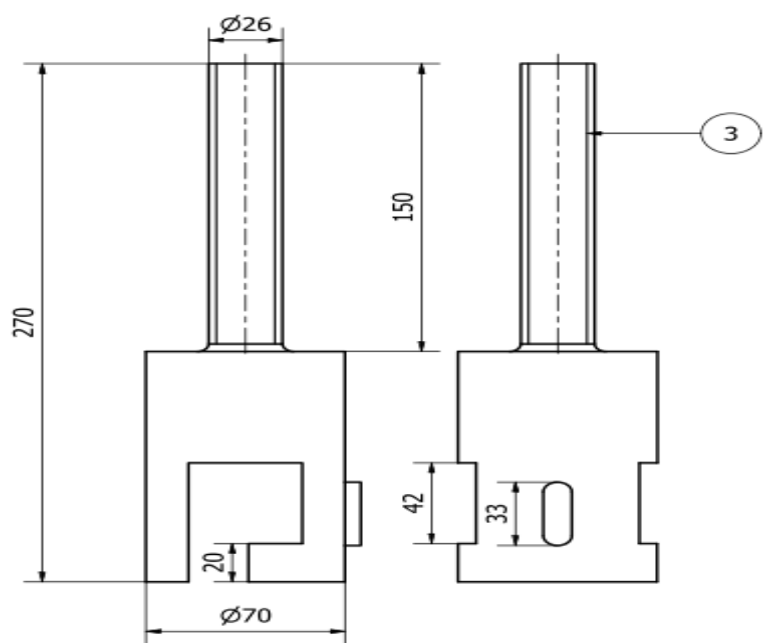

Gambar 3.3 Desain 2D (Pengait) Tool Pelepas Pin Guide Vane

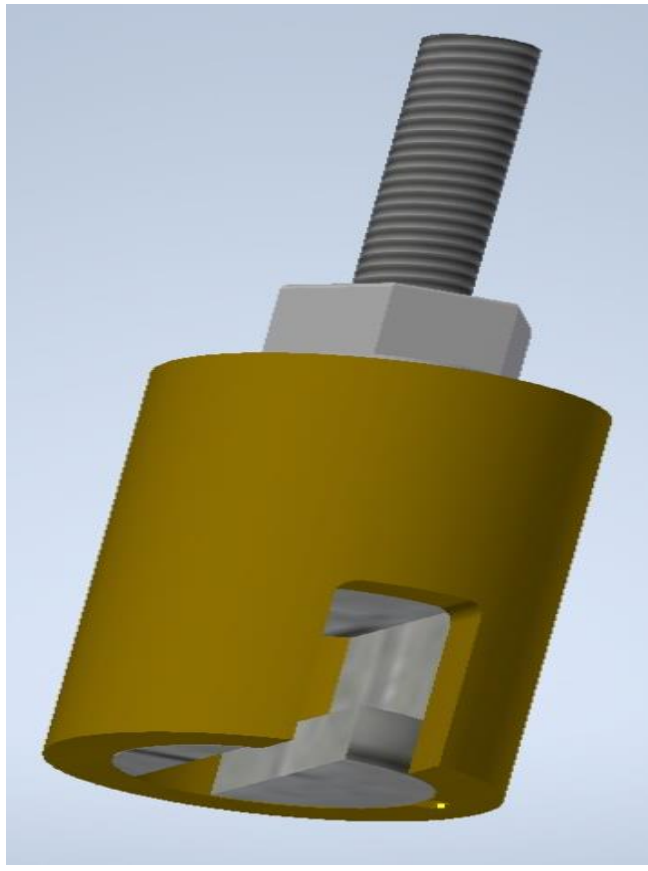

Gambar 3.4 Desain Tool Pelepas Pin Guide Vane

Pembuatan tool pelepas pin guide vane dikerjakan oleh bengkel bubut dan permesinan berdasarkan gambar desain.

\section{Implementasi Tools}

Implementasi tool pelepas pin guide vane telah dilakukan uji coba pada saat Major Inspection Turbin unit 2 di PLTA Ir. PM. Noor. Dengan menggunakan tool pelepas pin guide vane dapat dilepaskan dalam waktu 3 jam untuk 20 buah pin guide vane, jika dibandingkan dengan sebelum pemakaian tool pelepas pin guide vane maka mempercepat pekerjaan yang sebelumnya 2 hari menjadi 3 jam.

Semua pin guide vane dapat terlepas secara mulus tanpa mengalami kendala dan kerusakan, baik pada pin itu sendiri maupun pada liner arm dan guide vane. Namun saat pengujian diperlukan spacer, dalam hal ini menggunakan bearing bekas, untuk meningkatkan panjang tarikan pengait pin guide vane. 
HASIL DAN PEMBAHASAN

\section{Aspek Teknis}

\section{a. Perhitungan Tegangan - Regangan} Kekuatan luluh

$$
\begin{aligned}
& S_{y}=\frac{P_{y}}{A_{0}} \\
& 350 \mathrm{MPa} \\
& =\frac{P_{y}}{1249,567 \mathrm{~mm}^{2}} \\
& P_{y} \\
& =350 \mathrm{MPa} \\
& \times 1.249,567 \mathrm{~mm}^{2} \\
& P_{y} \\
& =437.348,45 \mathrm{~N}
\end{aligned}
$$

\section{Kekuatan Tarik}

$$
\begin{aligned}
& S_{u}=\frac{P_{\text {maksimum }}}{A_{0}} \\
& 420 \mathrm{MPa} \\
& =\frac{P_{\max }}{1249,567 \mathrm{~mm}^{2}} \\
& P_{\max } \\
& =420 \mathrm{MPa} \\
& \times 1.249,567 \mathrm{~mm}^{2} \\
& P_{\max } \\
& =524.818,14 \mathrm{~N}
\end{aligned}
$$

\begin{tabular}{|c|c|c|c|c|c|}
\hline \multirow[b]{2}{*}{ Constraint Name } & \multicolumn{3}{|c|}{ Reaction Force } & \multicolumn{2}{|c|}{ Reaction Moment } \\
\hline & Magnitude & $\begin{array}{r}\text { Comp } \\
(\underline{x} .\end{array}$ & $\begin{array}{l}\text { nent } \\
z)\end{array}$ & Magnitude & $\begin{array}{c}\text { Component } \\
(\underline{x, y}, \mathbf{z})\end{array}$ \\
\hline \multirow{3}{*}{ Fixed Constraint:1 } & \multirow{3}{*}{$10000 \mathrm{~N}$} & \multirow{2}{*}{\multicolumn{2}{|c|}{$10000 \mathrm{~N}$}} & \multirow{3}{*}{$130 \mathrm{~N} \mathrm{~m}$} & $-69,4777 \mathrm{~N} \mathrm{~m}$ \\
\hline & & & & & $0 \mathrm{~N} \mathrm{~m}$ \\
\hline & & \multicolumn{2}{|l|}{$\mathrm{ON}$} & & $109,876 \mathrm{~N} \mathrm{~m}$ \\
\hline Name & \multicolumn{2}{|l|}{ Minimum } & \multicolumn{3}{|c|}{ Maximum } \\
\hline Volume & \multicolumn{5}{|c|}{$1031040 \mathrm{~mm}^{\wedge} 3$} \\
\hline Mass & \multicolumn{5}{|l|}{$8,09364 \mathrm{~kg}$} \\
\hline Von Mises Stress & \multicolumn{2}{|c|}{$0,00000477678 \mathrm{MPa}$} & \multicolumn{3}{|c|}{$245,413 \mathrm{MPa}$} \\
\hline 1st Principal Stress & \multicolumn{2}{|c|}{$-62,0775 \mathrm{MPa}$} & \multicolumn{3}{|c|}{$111,844 \mathrm{MPa}$} \\
\hline 3rd Principal Stress & \multicolumn{2}{|l|}{$-315,03 \mathrm{MPa}$} & \multicolumn{3}{|c|}{$18,8111 \mathrm{MPa}$} \\
\hline Displacement & \multicolumn{2}{|l|}{$0 \mathrm{~mm}$} & \multicolumn{3}{|c|}{$0,0702493 \mathrm{~mm}$} \\
\hline Safety Factor & \multicolumn{2}{|l|}{ 1,42617 ul } & \multicolumn{3}{|l|}{$15 \mathrm{ul}$} \\
\hline Stress $X X$ & \multicolumn{2}{|c|}{$-259,822 \mathrm{MPa}$} & \multicolumn{3}{|c|}{$90,1488 \mathrm{MPa}$} \\
\hline Stress $\mathrm{XY}$ & \multicolumn{2}{|c|}{$-90,7092 \mathrm{MPa}$} & \multicolumn{3}{|c|}{$66,487 \mathrm{MPa}$} \\
\hline Stress XZ & \multicolumn{2}{|c|}{$-45,9684 \mathrm{MPa}$} & \multicolumn{3}{|c|}{$47,5978 \mathrm{MPa}$} \\
\hline Stress $\mathrm{W}$ & \multicolumn{2}{|c|}{$-151,208 \mathrm{MPa}$} & \multicolumn{3}{|c|}{$108,582 \mathrm{MPa}$} \\
\hline Stress YZ & \multicolumn{2}{|c|}{$-57,7927 \mathrm{MPa}$} & \multicolumn{3}{|c|}{$59,1287 \mathrm{MPa}$} \\
\hline Stress ZZ & \multicolumn{2}{|c|}{$-99,5612 \mathrm{MPa}$} & \multicolumn{3}{|c|}{$34,0368 \mathrm{MPa}$} \\
\hline X Displacement & \multicolumn{2}{|c|}{$-0,012089 \mathrm{~mm}$} & 0,044 & $1 \mathrm{~mm}$ & \\
\hline Y Displacement & $-0,0558601$ & $\mathrm{~mm}$ & 0,004 & $1891 \mathrm{~mm}$ & \\
\hline Z Displacement & $-0,00274206$ & $\mathrm{~mm}$ & 0,002 & $142 \mathrm{~mm}$ & \\
\hline
\end{tabular}

Dari perhitungan diatas, diketahui hasil $\mathrm{P}_{\mathrm{y}}=437.348,45 \mathrm{~N}$ dan $\mathrm{P}_{\operatorname{maz}}=524.818,14$ $\mathrm{N}$

\section{Safety Factor}

Untuk perhitungan safety factor asumsi tegangan yield strength $=437.348,45 \mathrm{~N}$, maka:

$$
\begin{aligned}
& (n)=\frac{S_{y}}{\sigma_{e}} \\
& (n)=\frac{350 \mathrm{MPa}}{437.348,45 \mathrm{~N}} \\
& (n)=0,0008 \\
& \quad \text { Maka Safety Factor min }= \\
& 0,0008
\end{aligned}
$$

\section{b. Pengujian dengan Software}

Pada pengujian tool dengan simulasi mengunakan software didapatkan hasil pengujian berupa von mises dan safety factor
Tabel 4.1 Hasil Pengujian Von Mises Stress dan Safety Factor

Berdasarkan Tabel 4.1 Hasil Pengujian Safety Factor dapat dilihat bahwa safety factor masih dibawah dari nilai safety factor material.

Tabel 4.2 Uji Keandalan Von Mises

\begin{tabular}{|l|l|}
\hline Nama Material & Steel, Carbon \\
\hline Yield Strength & $350 \mathrm{MPa}$ \\
\hline $\begin{array}{l}\text { Ultimate Tensile } \\
\text { Strength }\end{array}$ & $420 \mathrm{MPa}$ \\
\hline Magnitude & $10000.000 \mathrm{~N}$ \\
\hline Vector X & $0.000 \mathrm{~N}$ \\
\hline Vector Y & $-10000.000 \mathrm{~N}$ \\
\hline Vector Z & $0.000 \mathrm{~N}$ \\
\hline Von Mises Stress & $245,413 \mathrm{MPa}$ \\
\hline
\end{tabular}

Berdasarkan Tabel 4.2 Hasil Uji Keandalan dapat dilihat bahwa von mises stress masih dibawah dari nilai yield strength dari material. Dari data tersebut dapat disimpulkan bahwa Tool Pelepas Pin Guide Vane aman untuk digunakan. 


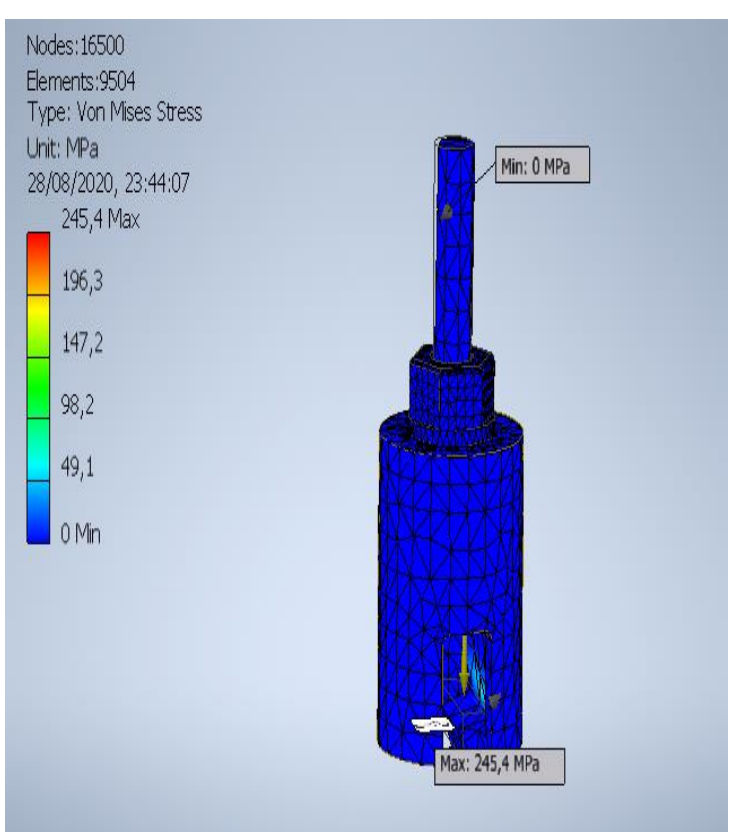

Gambar 4.1 Batas minimum dan maksimum von mises

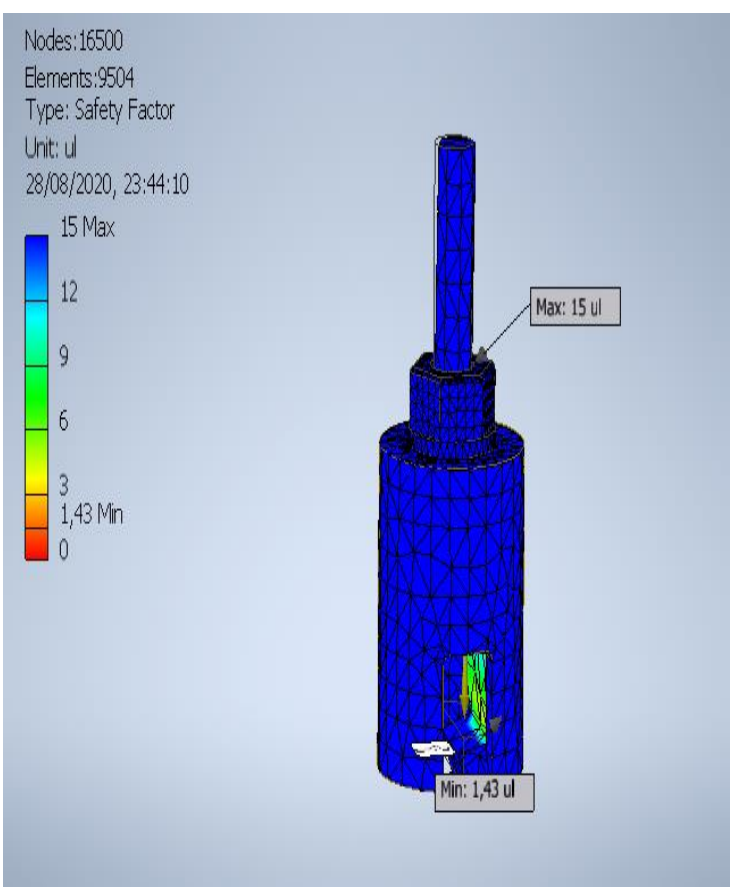

Gambar 4.2 Batas Minimum dan Maksimum Safety Factor

\section{Aspek Ekonomis}

\section{Manfaat Finansial}

Penggunaan Tool Pelepas Pin Guide Vane memang mempermudah dalam pelaksanaan pekerjaan, terutama pelepasan pin guide vane. Dengan menggunakan Tool Pelepas Pin Guide Vane maka pelepasan pin pada guide vane dengan cara lama (mengungkit dengan tuas) dapat digantikan dengan cara baru yaitu dengan menarik dengan sistem ulir.

Manfaat secara finansial dapat mempercepat pelaksanaan Major Inspection yang dalam pelaksanaan pekerjaan melepas pin guide vane memerlukan waktu \pm 2 hari, dapat dilakukan dalam \pm 3 jam saja. Hal ini sangat membantu dalam mempercepat pelaksanaan Major Inspection. Tool Pelepas Pin Guide Vane adalah sebuah tools dengan biaya produksi yang rendah, karena material yang diperlukan sekitar Rp. 1.850.000,- untuk 1 buah Tool Pelepas Pin Guide Vane.

\section{KESIMPULAN}

Adapun kesimpulan yang didapatkan dari Rancang Bangun Tool Pelepas Pin Guide Vane, yaitu sesuai dengan pengujian yang telah dilakukan baik menggunakan software Autodesk Inventor, maupun implementasi langsung pada unit yang dimaksud, adalah sebagai berikut:

1. Batas minimum von mises $0.00000478 \mathrm{MPa}$ dan maksimum $245.413 \mathrm{MPa}$

2. Nilai von mises stress masih dibawah dari nilai yield strength material yaitu $245.413 \mathrm{MPa}$

3. Mempersingkat dan mempermudah pelepasan pin guide vane.

4. Mencegah kejadian yang lebih fatal akibat kerusakan yang disebabkan oleh pelepasan pin guide vane menggunakan tool lama yang kurang aman.

5. Mempercepat pelaksanaan pemeliharaan Major Inspection selama kurang lebih dua hari.

\section{REFERENSI}

[1] Lukas, Daniel Rohi, Hanny Hosiana Tumbelaka. 2017. Studi Kinerja Pembangkit Listrik Tenaga Air (PLTA) di Daerah Aliran Sungai (DAS) Brantas. Jurnal Teknik 
Elektro, Vol. 10, No. 1, Maret 2017. 17-23.

[2] Hasriani, Muh. Said L, Andi Ferawati Jafar. 2017. Penerapan Media Pembangkit Listrik Tenaga Air (Plta) Terhadap Keterampilan Siswa. Jurnal Pendidikan Fisika Vol. 5 No. 2, September 2017. 89-95.

[3] Sugiyarto, Siti Qomariyah, Faizal Hamzah. 2013. Analisis Network Planning Dengan Cpm (Critical Path Method)Dalam Rangka Efisiensi Waktu Dan Biaya Proyek. e-Jurnal MATRIKS TEKNIK SIPIL Vol. 1 No. 4/Desember 2013,408-416.

[4] Muhammad Busyairi, La Ode Ahmad Safar Tosungku, Ayu Oktaviani. 2014. Pengaruh Keselamatan Kerja Dan Kesehatan Kerja Terhadap Produktivitas Kerja Karyawan. Jurnal Ilmiah Teknik Industri, Vol. 13, No. 2, Des 2014 112-124.

[5] Mafruddin, Marsuki. 2017. Pengaruh Bukaan Guide Vane Terhadap Kinerja Turbin Pikohidro Tipe Cross-Flow. Jurnal Teknik Mesin TURBO Vol. 6 No. 1. 2017, 31-37.

[6] Ulia Ridhani, Aminuddin, Riky Susanto, Adhim Abdul Jabbar. 2016. Rancang Bangun Alat Mounting Dan Dismounting Bearing Dengan Menggunakan Hydraulic Jack. JURNAL TEKNOLOGI TERPADU NO. 2 VOL. 4, Oktober 2016, 84-87.

[7] Rian Slamet Sutikno. 2010. Analisis Pengembangan Desain Konsep Treker Bearing Dengan Menggunakan Metode Quality Function Deployment (QFD). Tugas Akhir. Jurusan Teknik Industri, Fakultas Teknik Dan Ilmu Komputer, Universitas Komputer Indonesia. Bandung.

[8] PT PLN (Persero) UL PLTA Ir PM. Noor, Manual Book

[9] Callister, W.D., 1997. Material Science and Engineering, 4th Edition. New York: John Wiley and Sons. 